\title{
High-throughput amplicon sequencing reveals the spatiotemporal effects, abiotic and biotic shaping factors for the microbial communities in tropical mangrove sediments in Sanya, China
}

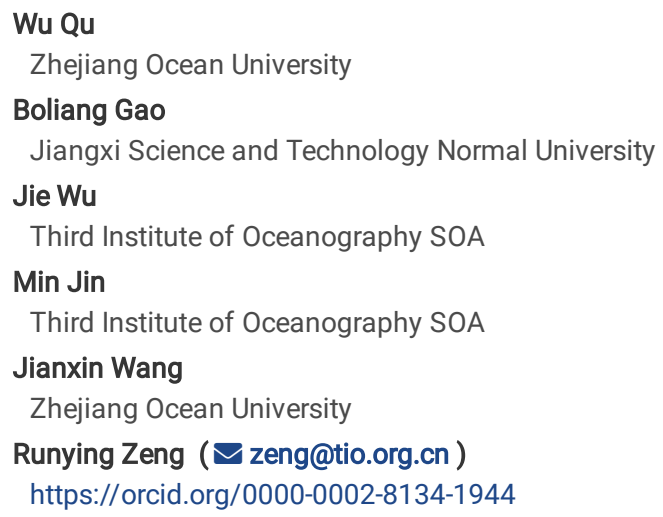

Research

Keywords: Mangroves, Spatiotemporal influences, Particle size, Keystone taxa

Posted Date: June 10th, 2020

DOl: https://doi.org/10.21203/rs.3.rs-34433/v1

License: (-) (1) This work is licensed under a Creative Commons Attribution 4.0 International License. Read Full License 


\section{Abstract \\ Background}

Microbial roles in element cycling and nutrient providing are crucial for mangrove ecosystems and serve as important regulators for climate change in Earth ecosystem. However, some key information about the spatiotemporal influences and abiotic and biotic shaping factors for the microbial communities in mangrove sediments remains lacking.

\section{Methods}

In this work, 22 sediment samples were collected from multiple spatiotemporal dimensions, including three locations, two depths, and four seasons, and the bacterial, archaeal, and fungal community structures in these samples were studied using amplicon sequencing.

\section{Results}

The microbial community structures were varied in the samples from different depths and locations based on the results of LDA effect size analysis, principal coordinate analysis, the analysis of similarities, and permutational multivariate ANOVA. However, these microbial community structures were stable among the seasonal samples. Linear fitting models and Mantel test showed that among the 13 environmental factors measured in this study, the sediment particle size (PS) was the key abiotic shaping factor for the bacterial, archaeal, or fungal community structure. Besides PS, salinity and humidity were also significant impact factors according to the canonical correlation analysis $(p \leq 0.05)$. Co-occurrence networks demonstrated that the bacteria assigned into phyla Ignavibacteriae, Proteobacteria, Bacteroidetes, Chloroflexi, and Acidobacteria were the key biotic factors for shaping the bacterial community in mangrove sediments.

\section{Conclusions}

This work showed the variability on spatial dimensions and the stability on temporal dimension for the bacterial, archaeal, or fungal microbial community structure, indicating that the tropical mangrove sediments are versatile but stable environments. PS served as the key abiotic factor could indirectly participate in material circulation in mangroves by influencing microbial community structures, along with salinity and humidity. The bacteria as key biotic factors were found with the abilities of photosynthesis, polysaccharide degradation, or nitrogen fixation, which were potential indicators for monitoring mangrove health, as well as crucial participants in the storage of mangrove blue carbons and mitigation of climate warming. This study expanded the knowledge of mangroves for the spatiotemporal variation, distribution, and regulation of the microbial community structures, thus further elucidating the microbial roles in mangrove management and climate regulation.

\section{Introduction}

Mangroves are productive wetland ecosystems in the world and occur in the intertidal zones on tropical and subtropical coast [1, 2]. Mangroves have attracted much research interest because of the various ecological functions of mangrove ecosystems, including runoff and flood prevention, storage and recycling of nutrients and wastes, cultivation, energy conversion, and their great significance on science and education [3]. Mangroves act as the interface of land, ocean, and atmosphere and are the centers for the flow of energy and matter among these ecosystems. Mangroves, as typical blue-carbon ecosystems, store considerable amounts of carbon (C) into the sediments, thus making them important regulators for climate change [4]. Therefore, mangroves are essential in the Earth ecosystem.

Microorganisms in mangroves are important. Universal studies on the structure and diversity patterns of microorganisms in mangrove sediments and leaves, including the communities of bacteria [5-7], archaea [7, 8], and fungi [9-11], have shown that the microorganisms in mangroves are important element cyclers and nutrient providers, thus elucidating the microbial roles for mangrove ecological functions. As we know, comprehensive information for the biotic and abiotic processes across space and time needs to be established to fully understand ocean ecosystems [12]. However, this key knowledge of mangrove microbial communities remains lacking. Specifically, the existing unilateral investigations on limited spatial and temporal dimensions cannot reveal the comprehensive effects of spatiotemporal variations on the microbial communities in mangroves [13,14]. The key abiotic and biotic factors that shape the mangrove microbial communities also need to be explored. These questions should be addressed to further understand the assembly of mangrove microbial communities, the roles of mangrove microorganisms in climate regulation, and the management of mangrove forests $[15,16]$.

In this study, we investigated three kinds of microbial communities, namely, bacteria, archaea, and fungi, in the sediments from tropic mangroves in Sanya City, along with 13 abiotic environmental factors from different spatial (two locations and two depths) and temporal (four seasons) dimensions. We aimed to determine the laws of spatiotemporal effects on microbial variations and reveal the key abiotic and biotic factors that shape the microbial communities, including bacteria, archaea, and fungi, in mangrove sediments.

\section{Results}

\section{Descriptions of sediment samples and abiotic environmental factors}


Bulk sediment samples were collected from the tropic mangroves located in Yalong Bay (YLW), Sanya River (SYH), and Tielu Bay (TLG) in Sanya City, China (Fig. 1A). Totally, 22 sediment samples were obtained from two depths (surface: 0-2 cm and subsurface: 12-14 cm), three locations (YLW, SYH, and TLG), and four seasons (March, June, September, and December). However, two samples from YLW in December were missing, because the sampling path was blocked by the municipal engineering unit. The sample name was formatted as "location_season_depth". For example, the name "YLW_6_surf" indicates that the sample was collected from the surface sediments of YLW mangroves in June, while "TLG_9_sub" indicates that the sample was collected from the subsurface sediments of TLG mangroves in September.

Thirteen environmental abiotic factors were collected, namely, salinity (SAL), sediment temperature (TEMP), pH, total nitrogen (TN), ammonium nitrogen $(\mathrm{AN})$, nitrate nitrogen (NN), total phosphorus (TP), total carbon (TC), organic carbon (OC), humidity (HUM), PS, monthly mean air temperature (MMT), and monthly mean precipitation (MMP). The DNA concentrations (DNA_C) extracted from the samples were also recorded in Table S1 along with those abiotic factors. Significant correlations ( $p \leq 0.05$ ) were found among these factors (Additional file 1: Fig. S1). SAL varied dramatically in seasonal samples, and PS distinctly differed in the samples from different locations (Additional file 1: Table S1).

\section{Compositions of the microbial communities}

Proteobacteria was the dominant phylum for bacterial community in all samples, and the phyla Bacteroidetes, Chloroflexi, Cyanobacteria, Planctomycetes, Acidobacteria, Firmicutes, Verrucomicrobia, Nitrospirae, Latescibacteria, Spirochaetae, Actinobacteria, and Gemmatimonadetes were detected in all sediment samples (Additional file 1: Fig. S2). Classes that belonged to phylum Proteobacteria were separately analyzed. Except for the YLW samples in June and September, delta- and gamma-proteobacteria classes were dominant in other samples (Fig. 1B).

For archaeal community, Euryarchaeota, Woesearchaeota_DHVEG-6, Bathyarchaeota, and Thaumarchaeota were the dominant phyla in the samples (Additional file 1: Fig. S3). The fungal phyla Glomeromycota, Chytridiomycota, Blastocladiomycota, Basidiomycota, and Ascomycota, as well as LKM15 and Cryptomycota, were discovered in the sediment samples (Additional file 1: Fig. S4). Ascomycota was the dominant phylum in most samples.

\section{Spatiotemporal Effects On The Alpha Diversities Of Microbial Communities}

The alpha diversities of bacterial, archaeal, and fungal communities were analyzed. For the bacterial community (Additional file 1: Fig. S5), the depth significantly affected (analysis of variance [ANOVA], $p \leq 0.05$ ) the diversity (based on Shannon and Simpson indices) and abundance (based on ACE and Chao indices). Significant difference was not found in the samples from different locations. However, for archaeal community (Additional file 1: Fig. S6), significant difference was observed in the alpha diversity of the samples obtained from different locations (ANOVA, $p \leq 0.05)$ but in different depths. For fungal community (Additional file 1: Fig. S7), location and depth could significantly affect the abundance indices (ACE and Chao indices, ANOVA, $p \leq 0.05$ ) but not the diversity indices (Shannon and Simpson indices). Significant difference was uniformly not detected in seasonal samples in the bacterial, archaeal, or fungal community.

\section{Spatiotemporal Effects On The Structures Of Microbial Communities}

According to the principal coordinate analysis (PCoA) and the 95\% confidence ellipses in the results, the location and depth have significant effect on microbial communities, including bacteria, archaea, and fungi (Fig. 2A). The structural patterns of bacterial and fungal communities from surface and subsurface sediments were obviously different. However, depth effect on archaeal community was not found (Fig. 2B). Seasonal impact was not detected in the bacterial, archaeal, or fungal community (Fig. 2C).

LDA effect size (LEfSe) analysis yielded similar results (Fig. 3 and Additional file 1: Fig. S7). Totally, 11 and 21 bacterial phyla with significant differences were detected in the samples from different locations and depths (LDA $\geq 2.5$ ), respectively, and only four bacterial phyla had significant difference in the samples from different seasons (LDA $\geq 2.5$ ). Correspondingly, differential phyla belonging to archaea and fungi were found with LDA values $\geq 2.5$ from location and depth samples. However, no differential species on phylum level was found in archaeal and fungal communities from seasonal samples.

Results from the analysis of similarities (ANOSIM) and permutational multivariate ANOVA (Adonis) supported the significant difference among the samples from different locations ( $p \leq 0.05$, Additional file 2: Table S2) in the bacterial, archaeal, or fungal community. ANOSIM and Adonis also supported that the depth could significantly affect bacterial and fungal communities ( $p \leq 0.05$, Additional file 2: Table S2). Similar with the PCoA result, no significant difference was found in the archaeal community from the depth samples based on the results of ANOSIM and Adonis (Additional file 2: Table S2). Moreover, no seasonal difference was found in bacterial, archaeal, and fungal communities (Additional file 2: Table S2).

\section{Abiotic Factor That Shape The Microbial Communities}

Four abiotic factors with variance inflation factors of more than 10 , including TN, NN, TC, and MMT, were removed because of their high collinearity with the other factors (Additional file 1: Table S3). Subsequently, canonical correlation analysis (CCA) was performed to assess the effects of abiotic environmental factors on the microbial communities (Fig. 4A). SAL, HUM, and PS were the abiotic factors that significantly affected the bacterial, archaeal, and fungal community ( $p \leq 0.05$, Additional file 3: Table S4). Additionally, AN, TP, OC, and pH were the significant abiotic factors for bacterial community, and TEMP could significantly affect the archaeal community. For fungal community, TP, OC, and pH were significant factors (Additional file 3: Table S4). 
To investigate the key abiotic factors that shaped the microbial communities, we individually fitted the significant factors from CCA results (Additional file 3 : Table S4) with the PC1 values from principal component analysis (PCA) by using the linear models. The factors possessed the highest $R^{2}$ value in the fitting models were identified as the key biotic factors for the microbial communities. Uniformly, PS had the highest $R^{2}$ value in the bacterial, archaeal, or fungal community (Fig. 4B and Additional file 1: Fig. S8).

Mantel test was performed to confirm this result, and this analysis supported that PS served as the key abiotic factor for the microbial communities. Results showed that among the abiotic environmental factors collected, PS possessed the highest $R^{2}$ value and a significant $p$ value $(p \leq 0.05)$ in the bacterial, archaeal, or fungal community (Table 1).

Table 1

Mantel test results between the matrixes of the abiotic environmental factors and microbial communities

\begin{tabular}{|lllllll|}
\hline Environmental factors & \multicolumn{2}{l}{ Bacterial community } & \multicolumn{2}{l}{ Archeal community } & \multicolumn{2}{l|}{ Fungal community } \\
\cline { 2 - 7 } & $\mathbf{R}^{2}$ & $\mathbf{p ~ v a l u e}$ & $\mathbf{R}^{2}$ & $\mathbf{p}$ value & $\mathbf{R}^{2}$ & $\mathbf{p}$ value \\
\hline SAL & 0.2791 & 0.01 & 0.0297 & 0.746 & 0.1194 & 0.349 \\
\hline TEMP & -0.1506 & 0.073 & 0.0872 & 0.438 & -0.2459 & 0.081 \\
\hline AN & 0.0133 & 0.898 & -0.0882 & 0.435 & 0.0942 & 0.537 \\
TP & 0.1402 & 0.041 & 0.0597 & 0.425 & 0.1241 & 0.175 \\
OC & 0.057 & 0.453 & 0.0072 & 0.923 & 0.0607 & 0.547 \\
pH & 0.1517 & 0.057 & -0.0561 & 0.538 & 0.1123 & 0.34 \\
\hline HUM & 0.3619 & 0.001 & 0.1326 & 0.155 & 0.3457 & 0.01 \\
\hline PS & 0.4417 & 0.001 & 0.3376 & 0.003 & 0.4257 & 0.001 \\
\hline MMP & -0.0707 & 0.227 & -0.0303 & 0.582 & 0.0015 & 0.983 \\
\hline
\end{tabular}

\section{Biotic Factors That Shape The Bacterial Communities}

Co-occurrence networks from microbial communities were used to assess the keystone taxa that shaped the microbial communities in mangrove sediments. For bacterial community, networks were built for three locations (Fig. 5A for SYH, 5B for TLG, and 5C for YLW). Based on these networks, the values of among-module connectivities $(\mathrm{Pi})$ and within-module connectivities $(\mathrm{Zi})$ were calculated to assess the keystone taxa $(\mathrm{Zi}>2.5$ or/and $\mathrm{Pi}>0.62)$ for each location.

Results showed that five keystone taxa (operational taxonomic unit [OTU]5273, OTU5037, OTU5104, OTU5013, and OTU12246) were found in SYH samples, 12 keystone taxa (OTU11764, OTU11887, OTU12355, OTU11459, OTU11559, OTU6475, OTU11996, OTU7966, OTU10701, OTU16075, OTU12101, and OTU11086) were found in TLG samples, and only one OTU was assessed as keystone taxon (OTU2963) in YLW samples (Fig. 5D). These keystone taxa were assigned into phyla Ignavibacteriae, Proteobacteria, Bacteroidetes, Chloroflexi, and Acidobacteria (Table 2). However, we did not obtain any keystone taxon information for archaeal and fungal communities from the data. 
Table 2

Taxonomic information of the keystone taxa for the bacterial community

\begin{tabular}{|c|c|c|c|c|c|c|}
\hline OTU ID & Location & Phylum & Class & Order & Family & Genus \\
\hline OTU5273 & SYH & Ignavibacteriae & Ignavibacteria & Ignavibacteriales & PHOS-HE36 & norank \\
\hline OTU5037 & SYH & Proteobacteria & Alphaproteobacteria & Sphingomonadales & Erythrobacteraceae & unclassified \\
\hline OTU5104 & SYH & Proteobacteria & Gammaproteobacteria & Xanthomonadales & unclassified & unclassified \\
\hline OTU5013 & SYH & Ignavibacteriae & Ignavibacteria & Ignavibacteriales & Ignavibacteriaceae & Ignavibacterium \\
\hline OTU12246 & SYH & Proteobacteria & Alphaproteobacteria & Rhodospirillales & Rhodospirillaceae & Defluviicoccus \\
\hline OTU11764 & TLG & Proteobacteria & Gammaproteobacteria & Gammaproteobacteria_Incertae_Sedis & unknown & norank \\
\hline OTU11887 & TLG & Proteobacteria & Gammaproteobacteria & Xanthomonadales & JTB255 & norank \\
\hline OTU12355 & TLG & Proteobacteria & Alphaproteobacteria & Rhodobacterales & Rhodobacteraceae & unclassified \\
\hline OTU11459 & TLG & Proteobacteria & Alphaproteobacteria & Rhodospirillales & $\begin{array}{l}\text { Rhodospirillales } \\
\text { Incertae Sedis }\end{array}$ & $\begin{array}{l}\text { Candidatus } \\
\text { Alysiosphaera }\end{array}$ \\
\hline OTU11559 & TLG & Proteobacteria & Gammaproteobacteria & unclassified & unclassified & unclassified \\
\hline OTU6475 & TLG & Bacteroidetes & Cytophagia & Cytophagales & Flammeovirgaceae & norank \\
\hline OTU11996 & TLG & Bacteroidetes & Bacteroidia & Bacteroidia_Incertae_Sedis & Draconibacteriaceae & unclassifiede \\
\hline OTU7966 & TLG & Proteobacteria & Deltaproteobacteria & Desulfobacterales & Desulfobulbaceae & Desulfopila \\
\hline OTU10701 & TLG & Chloroflexi & unclassified & unclassified & unclassified & unclassified \\
\hline OTU16075 & TLG & Chloroflexi & JG30-KF-CM66 & norank & norank & norank \\
\hline OTU12101 & TLG & Chloroflexi & Dehalococcoidia & MSBL5 & norank & norank \\
\hline OTU11086 & TLG & Bacteroidetes & Flavobacteriia & Flavobacteriales & Flavobacteriaceae & Robiginitalea \\
\hline OTU2963 & YLW & Acidobacteria & Acidobacteria & norank & norank & norank \\
\hline
\end{tabular}

Discussion

\section{Inconsistency over the comparison of influence degree on the bacterial community in mangrove sediments between marine and terrestrial environments}

Phyla Cyanobacteria and Chloroflexi [17] and class gamma-Proteobacteria [18] are typical bacterial communities in marine environments, and phyla Actinobacteria, Acidobacteria, and Verrucomicrobia [19-21] and classes alpha- and beta-Proteobacteria [22] are mainly found in terrestrial environments. The relative abundances of these communities could assess the influence degree on the bacterial community in mangrove sediments from marine and terrestrial environments [23].

Mangrove eco-systems, as typical intertidal wetlands, could be affected by the land and ocean. Marine environment has strong effect on the bacterial and viral communities in mangrove sediments, indicating the higher influence from oceans than that from land [7, 24]. For 16 out of 22 samples in this study, the relative abundances of marine bacteria were greater than those from land, thus supporting former studies (Fig. 1B and Additional file 1: S2). However, for the six remaining samples, the relative abundances of terrestrial communities were greater than those from oceans (Figs. 1B and Additional file 1: S2). This result is inconsistent with previous research, indicating that the comparison of influence degree between oceans and land could be more variable than previously observed. For example, anthropogenic factors can complicate this variation [23].

\section{Microbial community structures in mangrove sediments showed spatial variability and temporal stability}

Location affected the alpha diversities of archaeal (Additional file 1: Fig. S5) and fungal communities (Additional file 1: Fig. S6), and ANOSIM, Adonis (Additional file 2: Table S2), LEfSe (Fig. 3A), and PCoA (Fig. 2A) results supported the significant influence of the location on bacterial, archaeal, or fungal community structure. Depth could also significantly affect the alpha diversities and structures of bacterial and fungal communities (Additional file 1: Figs. S4, S6, Figs. 2B, 3B and Additional file 2: Table S2). To avoid the effects of rhizosphere in mangroves [25], we only collected the bulk sediments away from the plant roots. However, the location and depth were still the significant spatial dimensions that shaped the microbial communities in mangrove sediments, suggesting that the distribution of microbial communities in mangrove sediments was highly territorialized in a fairly close sampling range (e.g., in the same city for sampling).

Our work failed to detect significant differences among the seasonal samples. The influence of spatial dimensions supports previous studies [7, 26, 27]. However, the weak effect from temporal dimension, namely, seasonal change, is unusual, especially for fungi with dynamic community structure in 
mangrove sediments [28]. We attribute this difference to the stable abiotic factors, except SAL and PS (Fig. S1), among the seasonal samples from the tropics, as previously reported [7].

Generally, our work demonstrated the variability in spatial dimensions and stability in temporal dimension of the microbial communities in tropical mangroves in Sanya City. This characteristic not only ensures the diversity of microbial functions in the different areas of mangrove sediments, but also guarantees the stability of the microbial functions against time variation, indicating a versatile but stable environment in tropical mangrove sediments.

\section{PS served as the key abiotic factor for shaping the microbial communities in mangrove sediments}

Limited studies focus on the key abiotic factors that shape the microbial communities in mangrove sediments. Among at least 13 abiotic factors that we collected in this work, PS was the key abiotic shaping factor for the bacterial, archaeal, or fungal community according to the results of linear fitting models (Fig. 4B, Additional file 1: Figs S8 and S10) and Mantel test (Table 2).

To the best of the authors' knowledge, this study first demonstrated PS as a key shaping factor for the microbial communities in mangrove sediments. The influence of PS on mangrove microbial diversity has been reported before, which showed that PS could affect the diversity and abundance of laccase-like bacteria, and their abundance decrease in the order of sand > clay > silt in Mai Po mangrove sediments of China [29]. Our work enhanced the value of PS for the assembly of not only the laccase-like bacteria but also three typical microbial communities in mangrove sediments.

The possible reasons of the PS influence on microbial structures are as follows: (i) High nutritional content is present in the soils or sediments with specific PS [30,31]. The difference in nutritional contents resulted in the variation in the structures of microorganisms. (ii) Soils or sediments with small PS could provide microbes a protective habit from predators [32,33]. Therefore, high abundance of microbes is often detected in samples with small PS. (iii) The crucial enzymes, such as urease, invertase, alkaline phosphatase, and xylanase, for bacterial survival are rich in sediments with specific PS [34-37] and could cause the abundance and diversity of microbes in the present samples. (iv) Permeability influenced microbial structures as confirmed by Probandt et al. [38], and PS is the sole variable that affects the permeability calculation of soils or sediments [39]. Thus, PS could affect the microbial structure by controlling the permeability of sediment samples.

In addition to PS, SAL and HUM were also uniform significant abiotic factors for bacterial, archaeal, and fungal communities (Fig. 4A and Additional file 3: Table S4). Considering the element cycling functions of these microorganisms in mangrove sediments, the above factors might indirectly influence carbon, nitrogen, and sulfur cycles in mangrove sediments by affecting the microbial community structures.

\section{Providers of bioavailable carbohydrates and ammonia nitrogen served as the key biotic factor for shaping the bacterial communities in mangrove sediments}

Keystone taxa are known as "the engineers" for shaping the community structures in nature because of their high connectivity with other species in the cooccurrence structures. Therefore, the keystone taxa are crucial biotic factors shaping the microbial communities in mangrove sediments. We failed to obtain any information about archaeal and fungal communities because of the possible weak dependency among these microorganisms and the possible interactions of archaeal and fungal communities with other living organisms rather than the creatures of their own kinds. Unlike archaea and fungi, keystone taxa were found in bacterial community. Results showed that the OTUs belonging to phyla Ignavibacteriae, Proteobacteria, Bacteroidetes, Chloroflexi, and Acidobacteria served as the bacterial keystone taxa in Sanya mangrove sediments (Table 2).

Interestingly, 16 out of 18 of these OTUs provided nitrogen and carbohydrates (Table 2). In detail, OTU5273 and 5013, which belong to the order Ignavibacteriales, are photoautotrophic green sulfur bacteria [40, 41]. The order Rhodospirillales (OTU12246 and 11459) and the family Rhodobacteraceae (OTU12355) are photoautotrophic bacteria [42, 43] and nitrogen (N) fixers [44-46]. Erythrobacteraceae (OTU5037) is also an important photoautotrophic family [47]. Desulfobulbaceae (OTU7966) is a sulfate-reducing bacteria that can actively oxidize $\mathrm{H}_{2}$, reduce sulfate, fix $\mathrm{CO}_{2}$ [48], and mediate $\mathrm{N}$ fixation in the oceans [49]. Some members of the phyla Chloroflexi (OTU10701, 16075, and 12101) and Acidobacteria (OTU2963) are also photoautotrophic bacteria [41]. In addition, the families Flavobacteriaceae (OTU11086) [50, 51], Flammeovirgaceae (OTU6475) [52, 53], and Draconibacteriaceae (OTU11996) [54, 55] and the order Xanthomonadales (OTU5104 and 11887) [56] degrade stable polysaccharides into active monosaccharides.

Polysaccharides, including cellulose and seaweed polysaccharide, are important storage forms of organic C in mangrove sediments [57, 58]. However, recalcitrant polysaccharides are difficult to utilize for many microorganisms. Mangroves can also store considerable dissolved inorganic carbons that cannot be utilized by many microorganisms [57]. Therefore, photo-autotrophic and polysaccharide-degrading bacteria can server as the keystone abiotic factors by providing bioavailable carbohydrates to other bacteria that interacted with them, as shown in the results of this work. Mangrove ecosystems also have a typical $\mathrm{N}$-deficient environment [59]. Therefore, the keystone OTUs with $\mathrm{N}$-fixation ability in the present study can provide bioavailable ammonia nitrogen for the survival of other microorganisms and living organisms in mangrove sediments. Hence, these keystone species could serve as the centers for bacterial interaction in mangrove sediments because of the nutrition that they provide.

These keystone species drive the microbial structure and function [60] and predict changes in microbial community [61]; hence, their status, especially for bifunctional species that can fix both $\mathrm{C}$ and $\mathrm{N}$, is important not only for themselves but also for many other bacteria that depend on them. Therefore, the changes of community structure of these keystone species provided in this work were potential important indicators for supervising the health of mangrove ecosystems. 


\section{Important contributions of the bacterial modules centered on photoautotrophic keystone taxa in mangrove sediments to the global climate}

The abundances of keystone species were not dominant in natural environments and in our work, but these taxa are the centers of co-occurrence structures in bacterial community, suggesting that they could organize many bacterial species together and form considerable interaction modules [60]. These bacterial modules might contribute to the ecological functions of mangroves, which are typical blue carbon ecosystems [4].

These bacterial co-occurrence modules centered on photoautotrophic keystone taxa could import inorganic $\mathrm{CO}_{2}$ into the sediments and support the survival of heterotrophic bacteria in the modules to form and store large amounts of organic carbons in microorganisms. Furthermore, the carbon fixed in mangrove sediments could be exported into the oceans [57], while some could be sealed up as recalcitrant dissolved organic matters in oceans for millions of years by the marine microbial carbon pump [62]. $\mathrm{N}$ fixation is another key function for some of these keystone taxa. Ammonia nitrogen, the product of $\mathrm{N}$ fixation, is an essential nutrient for living organisms, including primary producers, and nitrate, the product of nitrification of ammonia nitrogen, is crucial for the photosynthesis of phytoplankton [63]. The keystone taxa with $\mathrm{N}$ fixation ability could further increase the amount of $\mathrm{C}$ fixation by providing the limited nitrogenous nutrients for photosynthesis. In brief, these bacterial modules centered on photoautotrophic keystone taxa could be the additional $\mathrm{C}$ fixers and storage sites besides the large phytobenthos in mangroves and serve as potential vital participants in the storage of blue carbons and mitigation of climate warming.

Our work aimed to reveal the spatiotemporal influence and the key abiotic and biotic shaping factors for the microbial communities in mangrove sediments through amplicon sequencing and to reflect the structural information of mangrove microorganisms. However, we did not research and discuss the functional information about these communities. Hence, metagenomic and meta-transcriptomic sequencing should be conducted to describe the microbial communities for future works in mangrove ecosystems.

\section{Conclusions}

This study focused on determining the spatiotemporal influence and the abiotic and biotic shaping factors for the microbial communities in Sanya tropical mangrove sediments. Results showed variability on spatial dimensions (e.g., locations and depths) and stability on temporal dimension (seasons) of bacterial, archaeal, or fungal communities, which ensured the diversity of microbial functions in the different areas of mangrove sediments and guaranteed the stability of the microbial functions against time variation, indicating that the tropical mangrove sediments are versatile but stable environments.

PS was the key abiotic shaping factor for the bacterial, archaeal, or fungal communities, suggesting that PS along with other significant influence factors, such as SAL and HUM, could indirectly participate in the material circulation in mangroves by influencing microbial community structures.

Furthermore, our work found that photoautotrophic, $\mathrm{N}$-fixing, and polysaccharide-degrading bacterial keystone taxa served as the key biotic factors for shaping the bacterial community in mangrove sediments. Hence, the providers of bioavailable carbohydrates and ammonia nitrogen are essential for shaping the bacterial communities in mangrove sediments. These keystone taxa are the potential indicators for monitoring the health of mangroves, and the bacterial modules centered on these photoautotrophic taxa are also crucial participants in the storage of mangrove blue carbons and the mitigation of climate warming.

Our study expanded the knowledge of mangrove ecosystems for the change, distribution, and regulation of the microbial community structure in sediments, thus further elucidating the microbial roles in mangrove management and climate change mitigation.

\section{Methods}

\section{Sampling and physicochemical analysis}

Sediment samples were collected from Yalong Bay Qingmei, Sanya River, and Linwang Tielu Mangrove Nature Reserve in Sanya, China (Fig. 1A). Approximately $500 \mathrm{~g}$ of bulk sediment sample was collected and placed into sterilized centrifuge tubes at each site and stored in dry ice. Samples were stored at $-80^{\circ} \mathrm{C}$ in an ultra-low-temperature freezer.

The SAL of sediments was determined using a handheld SAL meter (ATAGO, Japan). Sample HUM was defined as the percentage of the weight of water in the sample and that of wet sample. The MMT and MMP of the month in which the samples were obtained was queried at https://www.wunderground.com/history/. Laser particle size analyzer Nicomp 380 (PSS, USA) was used to determine sediment PS. The pH and contents of TN, TP, TC, AN, NN, and OC were measured by Qingdao Hengli Testing Co., Ltd. (China) following the national standards of China. Sediment TEMP was measured using an alcohol thermometer in situ.

\section{DNA Extraction, High-throughput Sequencing, And Data Processing}

DNA extraction was performed with PowerSoil DNA isolation kit (MO BIO, USA). For each sample, $0.5 \mathrm{~g}$ of sediments was used for DNA extraction, and the procedures were strictly operated in three replicates following the kit instructions. The repeated DNA from the same sample was pooled to avoid extraction bias. DNA quality was determined by $1 \%$ agarose gel electrophoresis and Nanodrop 2000 (Thermo, USA). 
Subsequently, 515F and 806R primers [64] with barcodes were used to amplify the $16 \mathrm{~S}$ rRNA genes of bacteria and archaea, and $817 \mathrm{~F}$ and $1196 \mathrm{R}$ primers [65] with barcodes were used to amplify the 18S rRNA genes of fungi in the samples. Amplicon sequences were amplified using TransStart FastPfu DNA polymerase (TransGen, China) with the following components: $4 \mu \mathrm{L}$ of FastPfu buffer, $2 \mu \mathrm{L}$ of dNTPs $(2.5 \mathrm{mM}), 0.8 \mu \mathrm{L}$ of forward primer ( $5 \mu \mathrm{M}), 0.8 \mu \mathrm{L}$ of reverse primer $(5 \mu \mathrm{M}), 0.4 \mu \mathrm{L}$ of FastPfu polymerase, $0.2 \mu \mathrm{L}$ of albumin from bovine serum, $10 \mathrm{ng}$ of DNA, and double distilled $\mathrm{H}_{2} \mathrm{O}$ to obtain a total volume of $20 \mu \mathrm{L}$. The amplification reaction was performed using the ABI GeneAmp ${ }^{\circledR} 9700$ PCR device (ABI, USA), and the PCR program was as follows: 1 cycle of pre-heating at $95^{\circ} \mathrm{C}$ for $3 \mathrm{~min} ; 27$ cycles of denaturation at $95^{\circ} \mathrm{C}$ for $30 \mathrm{~s}$, annealing at $55^{\circ} \mathrm{C}$ for $30 \mathrm{~s}$, and extension at $72{ }^{\circ} \mathrm{C}$ for $45 \mathrm{~s}$; one cycle of final extension at $72{ }^{\circ} \mathrm{C}$ for $10 \mathrm{~min}$; and storage at $10^{\circ} \mathrm{C}$ until halted by the user. Purified amplicons were pooled in equimolar and paired-end sequenced $(2 \times 300)$ on an Illumina MiSeq platform (Illumina, San Diego, USA) according to the standard protocols by Majorbio Bio-Pharm Technology Co. Ltd. (Shanghai, China).

Raw fastq files were quality-filtered using Trimmomatic and merged using FLASH based on the following criteria: (i) The reads were truncated at any site that receives an average quality score $<20$ over a 50 bp sliding window. (ii) Sequences with overlap of longer than 10 bp were merged according to their overlap with mismatch no more than $2 \mathrm{bp}$. (iii) The sequences of each sample were separated according to barcodes (exactly matching) and Primers (allowing 2 nucleotide mismatching), and reads containing ambiguous bases were removed.

OTUs were clustered with 97\% similarity cutoff using UPARSE (version 7.1, http://drive5.com/uparse/) with a novel 'greedy' algorithm that performs chimera filtering and OTU clustering simultaneously. The taxonomy of each 16S and 18S rRNA gene sequence was analyzed using the RDP classifier algorithm (http://rdp.cme.msu.edu/) against the Silva (SSU123) 16S rRNA and 18S rRNA_eukaryota databases with a confidence threshold of 70\%.

\section{Statistical analysis}

Alpha diversity indices were calculated using the mothur software (version v.1.30.1 http://www.mothur.org/wiki/Schloss_SOP\#Alpha_diversity) and were visualized using the ggpubr package of the $\mathrm{R}$ software. The bar graphs of bacterial, archaeal, and fungal communities were generated in the $\mathrm{R}$ software in accordance with the result of Qiime processing. PCoA was conducted using the "cmdscale()" function in R software based on the Bray-Curtis distance, and the graphs were generated using the ggpubr package of R. CCA was used to evaluate the influences of environmental factors on the bacterial and archaeal diversity patterns. The "cca()" function in the ade4 package of R was used to execute this analysis. The "vif.cca()" function in R was used to reveal the VIF values of abiotic environmental factors, and the factors with VIFs of more than 10 were removed until all the VIF values of abiotic factors were less than 10. PCA was conducted using the "principal()" function in the psych package of R, and the PC1 values were obtained from the PCA results. Linear equation fitting was used to determine the most important shaping factors for the microbial communities by using the "Im()" function with the "singular.ok = FALSE" parameter to void a singular fit. The factors with VIFs of less than 10 were fitted separately by using the PC1 values from PCA results. Base on the $p$ and $R^{2}$ values, the key factors were confirmed. LEfSe analysis was performed in http://huttenhower.sph.harvard.edu/galaxy/. The keystone taxa were analyzed in http://129.15.40.240/mena/, and the values of $\mathrm{Zi}$ and $\mathrm{Pi}$ were calculated with the default parameters. The OTUs with $\mathrm{Zi}>2.5$ or/and $\mathrm{Pi}>0.62 \mathrm{were}$ identified as the keystone taxa [66]. The bacterial co-occurrent networks were visualized using the Cytoscape software. To display the relationship among the environmental factors, we analyzed and visualized the correlation coefficient and significance by using the "corrgram(") function in the corrgram package of $\mathrm{R}$ with the Pearson method. ANOSIM, Adonis, and Mantel test were analyzed using the "anosim()", "adonis()", and "mantel.rtest()" functions in R with the Bray-Curtis distance and 999 permutation tests.

\section{Declarations}

\section{Ethics approval and consent to participate}

Not applicable.

\section{Consent for publication}

Not applicable.

\section{Availability of data and materials}

Raw sequencing data in this study were deposited in the NCBI SRA database under accession no. SRR7637174- 7637195 and SRR7658014- 7658021.

\section{Competing interests}

The authors declare that they have no competing interests.

\section{Funding}

This research was supported by grants from National Key R\&D Program of China (2019YFD0901305); the Scientific Research Foundation of Third Institute of Oceanography, MNR (2019013); Science and Technology Program of Zhoushan (2019C21011).

\section{Authors' contributions}

Wu Qu and Runying Zeng designed and wrote this manuscript; Wu Qu performed the data analysis; Wu Qu, Boliang Gao and Jie Wu handled the samples; Jie Wu isolated the environmental DNA; Jianxing Wang and Runying Zeng revised the manuscript. 
We thank Miss Yanping Hou, Dr. Zhuhua Chan, Dr. Zhiwei Yi, Dr. Xinglin Chen for their assistance in sampling.

\section{References}

1. Luo L, Gu J-D. Nutrient limitation status in a subtropical mangrove ecosystem revealed by analysis of enzymatic stoichiometry and microbial abundance for sediment carbon cycling. International Biodeterioration Biodegradation. 2018;128:3-10.

2. Tue NT, Ngoc NT, Quy TD, Hamaoka H, Nhuan MT, Omori K. A cross-system analysis of sedimentary organic carbon in the mangrove ecosystems of Xuan Thuy National Park, Vietnam. J Sea Res. 2012;67:69-76.

3. Groot RSD. Functions of nature: evaluation of nature in environmental planning, management and decision making. Ecol Econ. 1995;14:211-3.

4. Alongi DM, Murdiyarso D, Fourqurean JW, Kauffman JB, Hutahaean A, Crooks S, Lovelock CE, Howard J, Herr D, Fortes M. Indonesia's blue carbon: a globally significant and vulnerable sink for seagrass and mangrove carbon. Wetlands Ecol Manage. 2016;24:3-13.

5. Machado LF, de Assis Leite DC, da Costa Rachid CTC, Paes JE, Martins EF, Peixoto RS, Rosado AS. Tracking mangrove oil bioremediation approaches and bacterial diversity at different depths in an in situ mesocosms system. Frontiers in microbiology. 2019;10:2107.

6. Moitinho MA, Bononi L, Souza DT, Melo IS, Taketani RG. Bacterial succession decreases network complexity during plant material decomposition in mangroves. Microbial ecology. 2018;76:954-63.

7. Zhou Z, Meng H, Liu Y, Gu J-D, Li M. Stratified bacterial and archaeal community in mangrove and intertidal wetland mudflats revealed by high throughput 16S rRNA gene sequencing. Frontiers in microbiology. 2017;8:2148.

8. Mukherji S, Ghosh A, Bhattacharyya C, Mallick I, Bhattacharyya A, Mitra S, Ghosh A. Molecular and culture-based surveys of metabolically active hydrocarbon-degrading archaeal communities in Sundarban mangrove sediments. Ecotoxicol Environ Saf. 2020;195:110481.

9. Haldar S, Nazareth SW. Diversity of fungi from mangrove sediments of Goa, India, obtained by metagenomic analysis using Illumina sequencing. 3 Biotech. 2019;9:164.

10. Vanegas J, Muñoz-García A, Pérez-Parra KA, Figueroa-Galvis I, Mestanza O, Polanía J. Effect of salinity on fungal diversity in the rhizosphere of the halophyte Avicennia germinans from a semi-arid mangrove. Fungal Ecology. 2019;42:100855.

11. Yao H, Sun X, He C, Maitra P, Li X-C, Guo L-D. Phyllosphere epiphytic and endophytic fungal community and network structures differ in a tropical mangrove ecosystem. Microbiome. 2019;7:57.

12. Sunagawa S, Acinas SG, Bork P, Bowler C, Acinas SG, Babin M, Bork P, Boss E, Bowler C, Cochrane G, et al. Tara Oceans: towards global ocean ecosystems biology. Nature Reviews Microbiology. 2020.

13. Denis N. Spatiotemporal microbial community composition in the subsurface sediments of tropical peat-draining rivers in Sarawak, Malaysia. 2019.

14. Kaestli M, Skillington A, Kennedy K, Majid M, Williams D, McGuinness K, Munksgaard N, Gibb K. Spatial and temporal microbial patterns in a tropical macrotidal estuary subject to urbanization. Frontiers in microbiology. 2017;8:1313.

15. Ansola G, Arroyo P, de Miera LES. Characterisation of the soil bacterial community structure and composition of natural and constructed wetlands. Sci Total Environ. 2014;473:63-71.

16. Arroyo P, de Miera LES, Ansola G. Influence of environmental variables on the structure and composition of soil bacterial communities in natural and constructed wetlands. Sci Total Environ. 2015;506:380-90.

17. Wietz M, Wemheuer B, Simon H, Giebel HA, Seibt MA, Daniel R, Brinkhoff T, Simon M. Bacterial community dynamics during polysaccharide degradation at contrasting sites in the $S$ outhern and A tlantic $O$ ceans. Environ Microbiol. 2015;17:3822-31.

18. Wang Y, Sheng H-F, He Y, Wu J-Y, Jiang Y-X, Tam NF-Y, Zhou H-W. Comparison of the levels of bacterial diversity in freshwater, intertidal wetland, and marine sediments by using millions of illumina tags. Appl Environ Microbiol. 2012;78:8264-71.

19. Bragina A, Berg C, Berg G. The core microbiome bonds the Alpine bog vegetation to a transkingdom metacommunity. Molecular ecology. 2015;24:4795807.

20. Kaiser K, Wemheuer B, Korolkow V, Wemheuer F, Nacke H, Schöning I, Schrumpf M, Daniel R. Driving forces of soil bacterial community structure, diversity, and function in temperate grasslands and forests. Scientific Reports. 2016;6:1-12.

21. Yun J, Ju Y, Deng Y, Zhang H. Bacterial community structure in two permafrost wetlands on the Tibetan Plateau and Sanjiang Plain, China. Microbial ecology. 2014;68:360-9.

22. Yun J, Zhang H, Deng Y, Wang Y. Aerobic methanotroph diversity in Sanjiang wetland, Northeast China. Microbial ecology. 2015;69:567-76.

23. Yun J, Deng Y, Zhang H. Anthropogenic protection alters the microbiome in intertidal mangrove wetlands in Hainan Island. Appl Microbiol Biotechnol. 2017;101:6241-52.

24. Jin M, Guo X, Zhang R, Qu W, Gao B, Zeng R. Diversities and potential biogeochemical impacts of mangrove soil viruses. Microbiome. 2019 ;7:58.

25. Wu P, Xiong X, Xu Z, Lu C, Cheng H, Lyu X, Zhang J, He W, Deng W, Lyu Y. Bacterial communities in the rhizospheres of three mangrove tree species from Beilun Estuary, China. PloS one. 2016;11:e0164082.

26. Behera P, Mohapatra M, Kim JY, Adhya TK, Pattnaik AK, Rastogi G. Spatial and temporal heterogeneity in the structure and function of sediment bacterial communities of a tropical mangrove forest. Environ Sci Pollut Res. 2019;26:3893-908.

27. Luo L, Wu R-N, Meng H, Li X-Y, Gu J-D. Seasonal and spatial variations in diversity and abundance of bacterial laccase-like genes in sediments of a subtropical mangrove ecosystem. International Biodeterioration Biodegradation. 2016;114:260-7. 
28. D'Souza J, Rodrigues BF. Seasonal diversity of arbuscular mycorrhizal fungi in mangroves of Goa, India. International Journal of Biodiversity. 2013; 2013.

29. Luo L, Zhou Z-C, Gu J-D. Distribution, diversity and abundance of bacterial laccase-like genes in different particle size fractions of sediments in a subtropical mangrove ecosystem. Ecotoxicology. 2015;24:1508-16.

30. Sessitsch A, Weilharter A, Gerzabek MH, Kirchmann H, Kandeler E. Microbial population structures in soil particle size fractions of a long-term fertilizer field experiment. Appl Environ Microbiol. 2001;67:4215-24.

31. Zhang P, Zheng J, Pan G, Zhang X, Li L, Rolf T. Changes in microbial community structure and function within particle size fractions of a paddy soil under different long-term fertilization treatments from the Tai Lake region, China. Colloids Surf B. 2007;58:264-70.

32. Postma J, van Veen JA. Habitable pore space and survival ofRhizobium leguminosarum biovartrifolii introduced into soil. Microb Ecol. 1990;19:149-61.

33. Oades JM. Soil organic matter and structural stability: mechanisms and implications for management. Plant soil. 1984;76:319-37.

34. Kandeler E, Stemmer M, Klimanek E-M. Response of soil microbial biomass, urease and xylanase within particle size fractions to long-term soil management. Soil Biol Biochem. 1999;31:261-73.

35. Kandeler E, Tscherko D, Bruce KD, Stemmer M, Hobbs PJ, Bardgett RD, Amelung W. Structure and function of the soil microbial community in microhabitats of a heavy metal polluted soil. Biol Fertil Soils. 2000;32:390-400.

36. Stemmer M, Gerzabek MH, Kandeler E. Organic matter and enzyme activity in particle-size fractions of soils obtained after low-energy sonication. Soil Biol Biochem. 1998;30:9-17.

37. Stemmer M, Gerzabek MH, Kandeler E. Invertase and xylanase activity of bulk soil and particle-size fractions during maize straw decomposition. Soil Biol Biochem. 1998;31:9-18.

38. Probandt D, Knittel K, Tegetmeyer HE, Ahmerkamp S, Holtappels M, Amann R. Permeability shapes bacterial communities in sublittoral surface sediments. Environ Microbiol. 2017;19:1584-99.

39. Gangi AF. Permeability of unconsolidated sands and porous rocks. Journal of Geophysical Research: Solid Earth. 1985;90:3099-104.

40. Cleary DFR, Polónia ARM, Sousa Al, Lillebø Al, Queiroga H, Gomes NCM. Temporal dynamics of sediment bacterial communities in monospecific stands of Juncus maritimus and Spartina maritima. Plant Biol. 2016;18:824-34.

41. Bryant DA, Liu Z, Li T, Zhao F, Costas AMG, Klatt CG, Ward DM, Frigaard N-U, Overmann J: Comparative and functional genomics of anoxygenic green bacteria from the taxa Chlorobi, Chloroflexi, and Acidobacteria. In Functional genomics and evolution of photosynthetic systems. Springer; 2012: 47102.

42. Imhoff JF, Hiraishi A, Süling J: Anoxygenic phototrophic purple bacteria. In Bergey's Manual® of Systematic Bacteriology. Springer; $2005: 119-132$.

43. Imhoff JF. Rhodobacter. Bergey's Manual of Systematics of Archaea and Bacteria. 2015:1-12.

44. Martínez-Pérez C, Mohr W, Schwedt A, Dürschlag J, Callbeck CM, Schunck H, Dekaezemacker J, Buckner CRT, Lavik G, Fuchs BM. Metabolic versatility of a novel N2-fixing Alphaproteobacterium isolated from a marine oxygen minimum zone. Environ Microbiol. 2018;20:755-68.

45. Collavino MM, Tripp HJ, Frank IE, Vidoz ML, Calderoli PA, Donato M, Zehr JP, Aguilar OM. nifH pyrosequencing reveals the potential for location-specific soil chemistry to influence N 2-fixing community dynamics. Environ Microbiol. 2014;16:3211-23.

46. Hoppe B, Kahl T, Karasch P, Wubet T, Bauhus J, Buscot F, Krüger D. Network analysis reveals ecological links between N-fixing bacteria and wooddecaying fungi. PLoS One. 2014; 9.

47. Tonon LAC, Moreira APB, Thompson F: The Family Erythrobacteraceae. In The Prokaryotes: Alphaproteobacteria and Betaproteobacteria. Edited by Rosenberg E, DeLong EF, Lory S, Stackebrandt E, Thompson F. Berlin, Heidelberg: Springer Berlin Heidelberg; 2014: $213-235$.

48. Leupin OX, Bernier-Latmani R, Bagnoud A, Moors H, Leys N, Wouters K, Stroes-Gascoyne S. Fifteen years of microbiological investigation in Opalinus Clay: a potential host rock for geologic radioactive waste depository. Swiss J Geosci. 2017;110:343-54.

49. Dekas AE, Chadwick GL, Bowles MW, Joye SB, Orphan VJ. Spatial distribution of nitrogen fixation in methane seep sediment and the role of the ANME archaea. Environ Microbiol. 2014;16:3012-29.

50. Larsbrink J, Zhu Y, Kharade SS, Kwiatkowski KJ, Eijsink VGH, Koropatkin NM, McBride MJ, Pope PB. A polysaccharide utilization locus from Flavobacterium johnsoniae enables conversion of recalcitrant chitin. Biotechnology for biofuels. 2016;9:260.

51. Barbeyron T, Lerat Y, Sassi J-F, Le Panse S, Helbert W, Collen PN. Persicivirga ulvanivorans sp. nov., a marine member of the family Flavobacteriaceae that degrades ulvan from green algae. Int J Syst Evol MicroBiol. 2011;61:1899-905.

52. Gao B, Jin M, Li L, Qu W, Zeng R. Genome sequencing reveals the complex polysaccharide-degrading ability of novel deep-sea bacterium Flammeovirga pacifica WPAGA1. Frontiers in microbiology. 2017;8:600.

53. Dong Q, Ruan L, Shi H. Genome sequence of a high agarase-producing strain Flammeovirga sp. SJP92. Standards in genomic sciences. $2017 ; 12: 13$.

54. Xu Z-X, Yu P, Mu D-S, Liu Y, Du Z-J. Tenacibaculum agarivorans sp. nov., an agar-degrading bacterium isolated from marine alga Porphyra yezoensis Ueda. Int J Syst Evol MicroBiol. 2017;67:5139-43.

55. Yu W-N, Du Z-Z, Chang Y-Q, Mu D-S, Du Z-J. Marinomonas agarivorans sp. nov., an agar-degrading marine bacterium isolated from red algae. Int J Syst Evol Microbiol. 2020;70:100-4.

56. Christensen P. Lysobacter. Bergey's Manual of Systematics of Archaea and Bacteria. 2015:1-11.

57. Alongi DM. Carbon cycling and storage in mangrove forests. Annual review of marine science. 2014;6:195-219.

58. Fujimoto K, Imaya A, Tabuchi R, Kuramoto S, Utsugi H, Murofushi T. Belowground carbon storage of Micronesian mangrove forests. Ecol Res. 1999;14:409-13. 
59. Lovelock CE, Feller IC, Ball MC, Engelbrecht BMJ, Ewe ML. Differences in plant function in phosphorus-and nitrogen-limited mangrove ecosystems. New Phytol. 2006;172:514-22.

60. Banerjee S, Schlaeppi K, van der Heijden MGA. Keystone taxa as drivers of microbiome structure and functioning. Nat Rev Microbiol. 2018;16:567-76.

61. Herren CM, McMahon KD. Keystone taxa predict compositional change in microbial communities. Environ Microbiol. 2018;20:2207-17.

62. Jiao N, Herndl GJ, Hansell DA, Benner R, Kattner G, Wilhelm SW, Kirchman DL, Weinbauer MG, Luo T, Chen F. The microbial carbon pump and the oceanic recalcitrant dissolved organic matter pool. Nat Rev Microbiol. 2011;9:555-5.

63. Kuypers MMM, Marchant HK, Kartal B. The microbial nitrogen-cycling network. Nat Rev Microbiol. 2018;16:263.

64. Fan W, Tang Y, Qu Y, Cao F, Huo G. Infant formula supplemented with low protein and high carbohydrate alters the intestinal microbiota in neonatal SD rats. BMC microbiology. 2014;14:279.

65. Rousk J, Bååth E, Brookes PC, Lauber CL, Lozupone C, Caporaso JG, Knight R, Fierer N. Soil bacterial and fungal communities across a pH gradient in an arable soil. ISME J. 2010;4:1340-51.

66. Deng Y, Jiang Y-H, Yang Y, He Z, Luo F, Zhou J. Molecular ecological network analyses. BMC Bioinform. 2012;13:113.

\section{Figures}

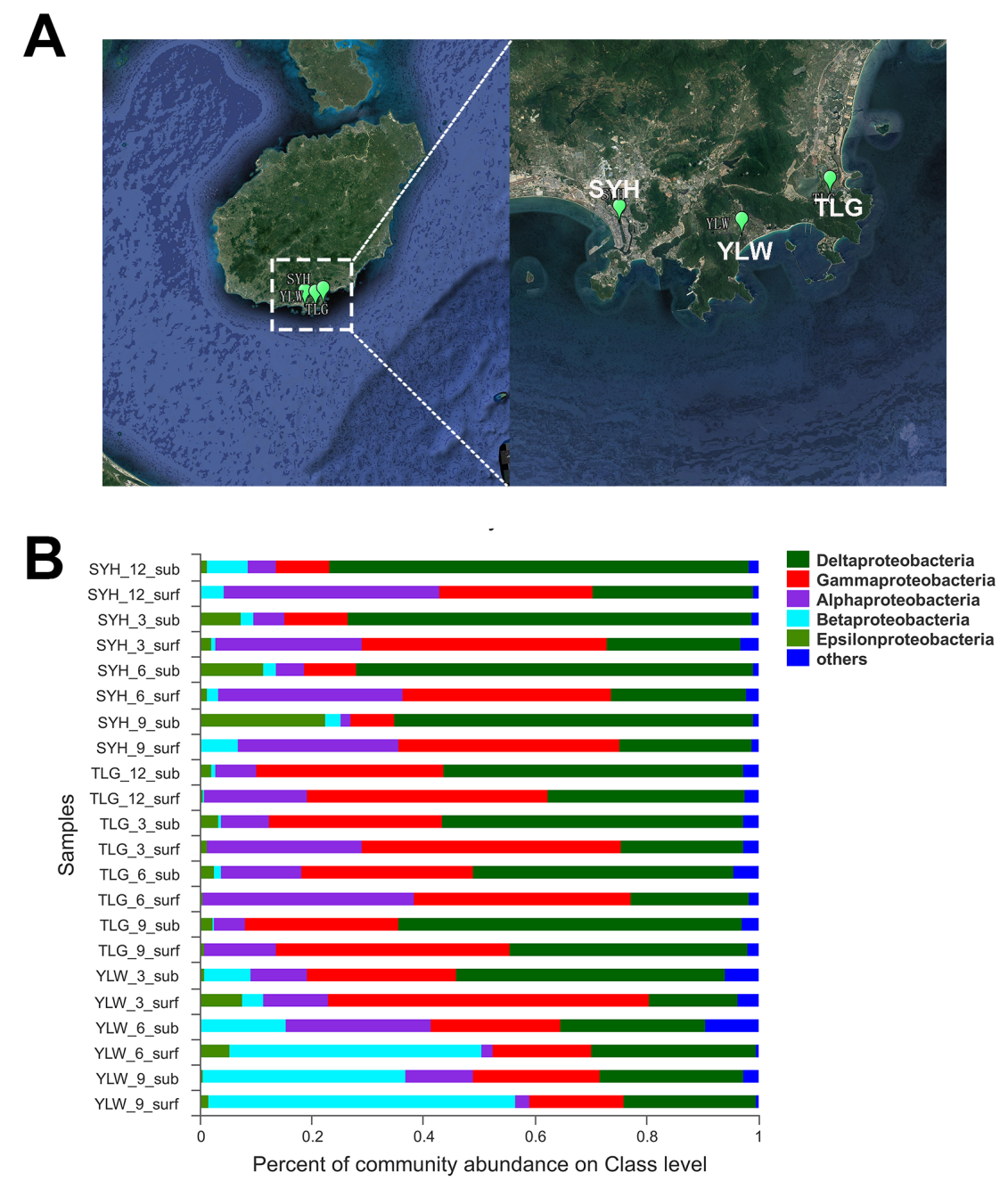

\section{Figure 1}

Sampling locations (A) in Sanya mangroves and the bacterial community composition from Proteobacteria phylum (B). YLW, Yalong Bay; SYH, Sanya River; and TLG, Tielu Bay. Note: The designations employed and the presentation of the material on this map do not imply the expression of any opinion whatsoever on the part of Research Square concerning the legal status of any country, territory, city or area or of its authorities, or concerning the delimitation of its frontiers or boundaries. This map has been provided by the authors. 
Bacteria

A location $\square$ SYH $\square$ TLG $\square$ YLW

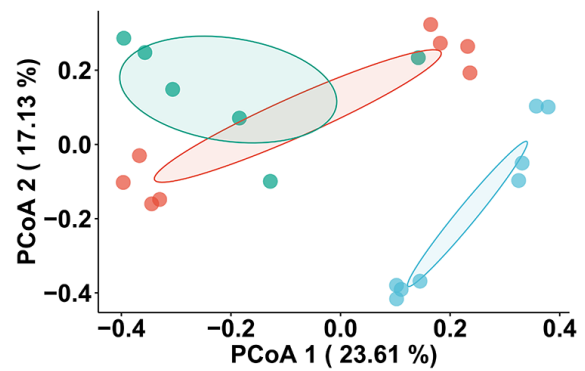

B depth $\square$ subsurface $\square$ surface

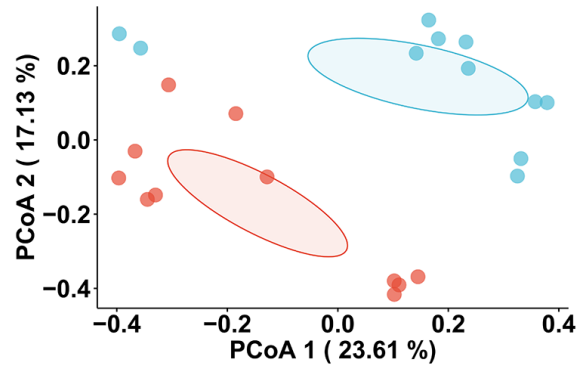

C season $\square$ Dec $\square$ Jun $\square$ Mar $\square$ Sep

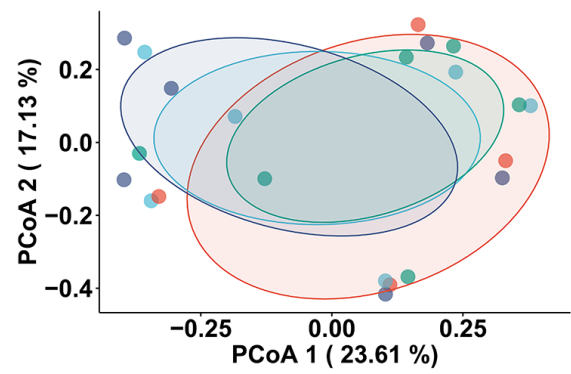

Archaea

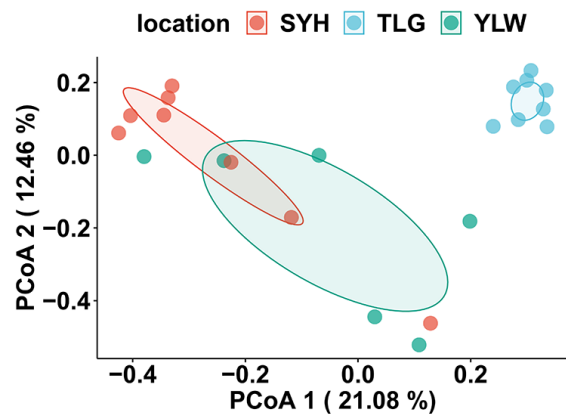

depth $\square$ subsurface $\square$ surface

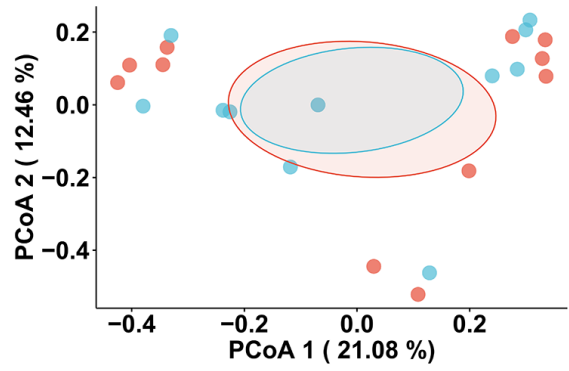

season $\square$ Dec $\square$ Jun $\square$ Mar $\square$ Sep

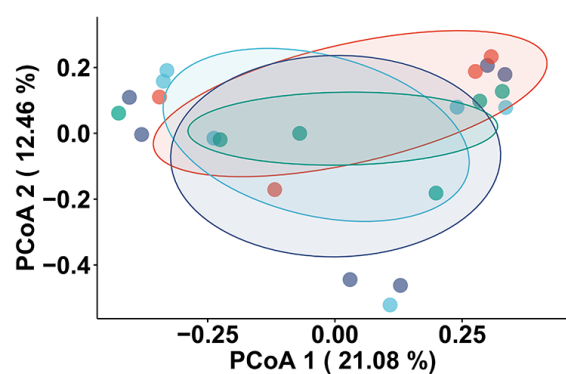

Fungi

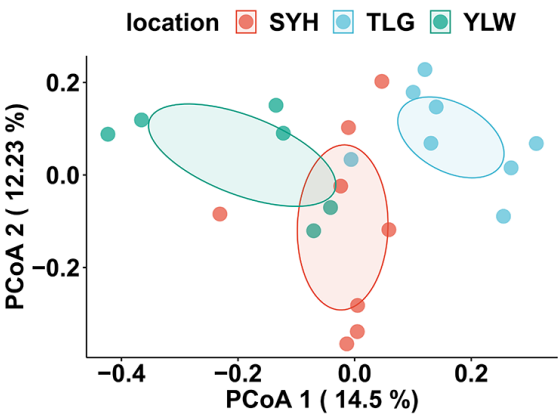

depth $\square$ subsurface $\square$ surface

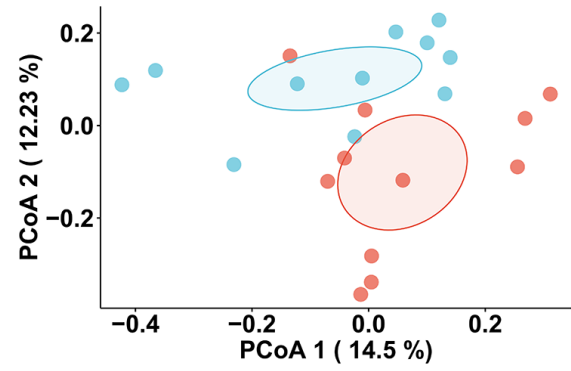

season $\square$ Dec $\square$ Jun $\square$ Mar $\square$ Sep

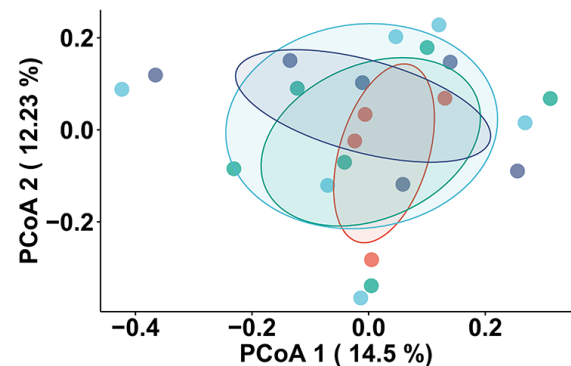

Figure 2

Principal coordinate analysis (PCOA) results of the microbial communities in mangrove sediments from multiple spatiotemporal dimensions. $A-C$ showed the PCoA results in the samples from different locations (A), depths (B), and seasons (C), respectively. According to the $95 \%$ confidence ellipses, the spatial dimensions, locations, and depths, could significantly affect the bacterial, archaeal, and fungal community structures ( $p \leq 0.05)$. However, seasons as temporal dimensions have no significant influence on any microbial community in mangrove sediments. 


\section{Bacteria}

A
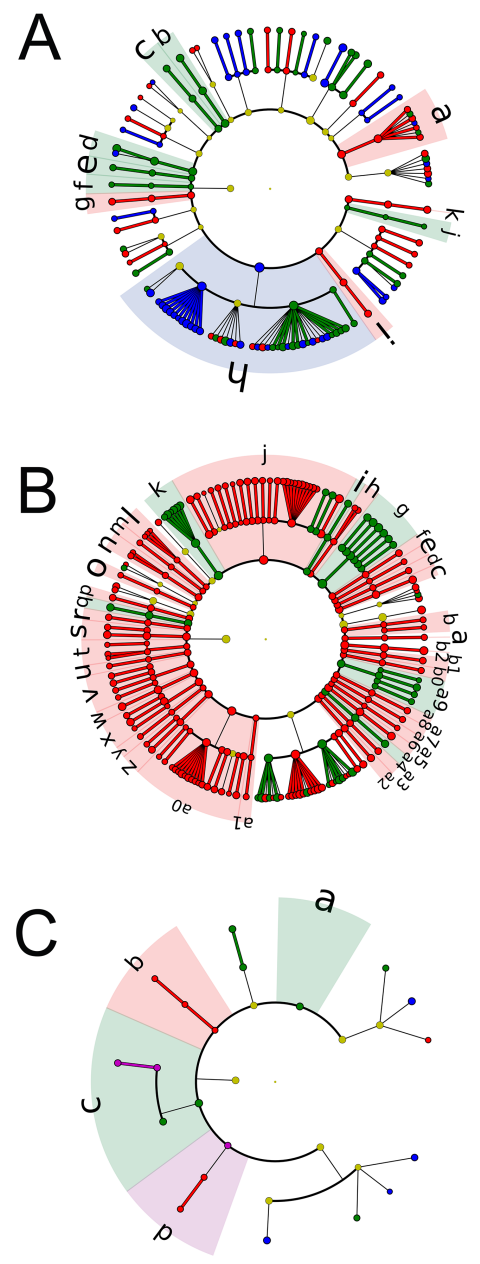

Archaea
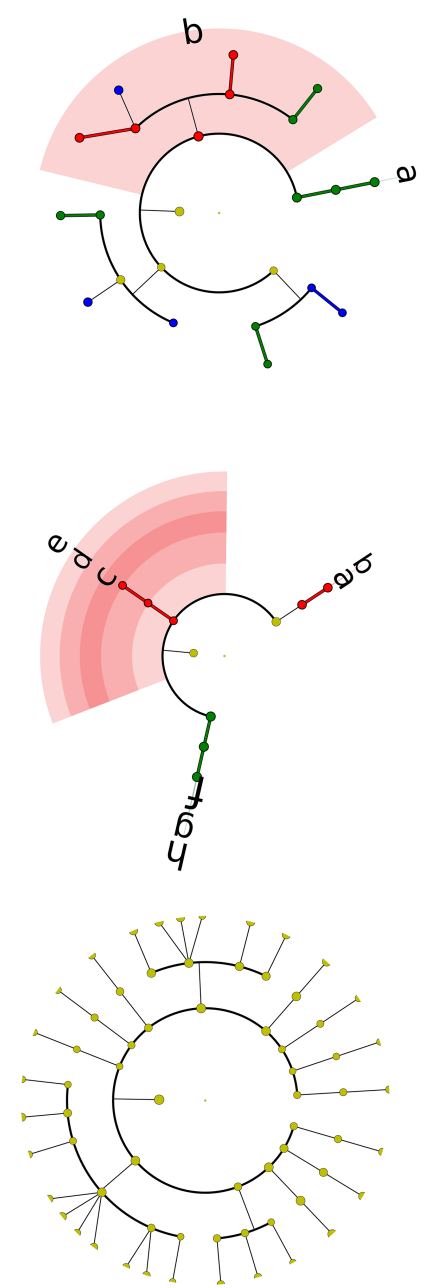

Fungi
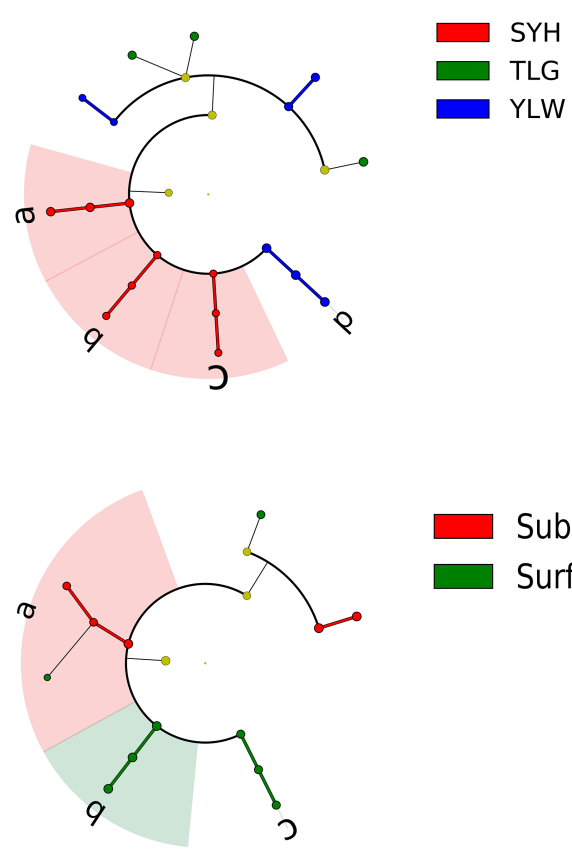

$\square$ Subsurface

Surface

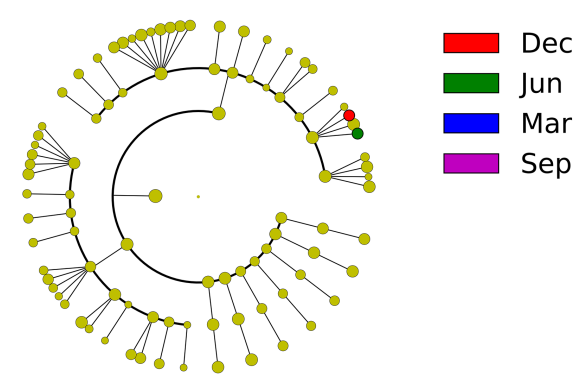

Figure 3

LDA effect size analysis for the microbial communities in mangrove sediments from multiple spatiotemporal dimensions. A-C show the results in the samples from different locations (A), depths (B), and seasons (C). Taxa on the phylum level with significantly different relative abundances were found in the bacterial, archaeal, and fungal community structures from the spatial samples. However, no phylum with significant different relative abundance was found in the temporal samples (see Fig. S7 for detailed legend information). 
Bacteria

A

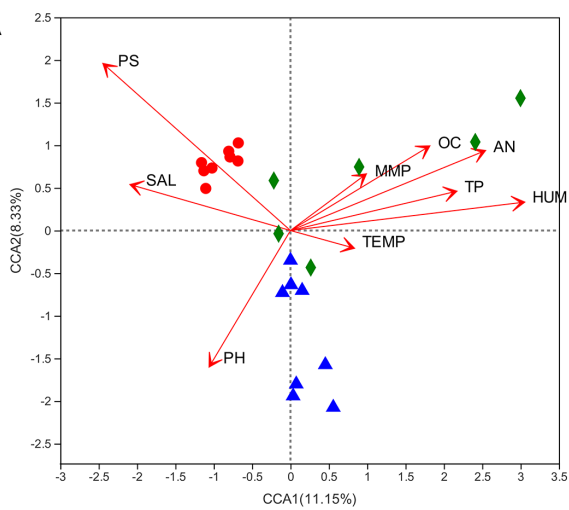

B

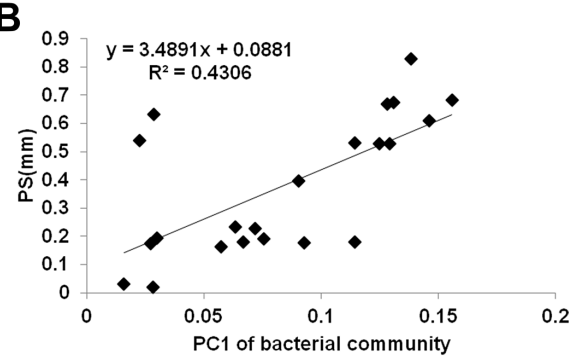

Archaea
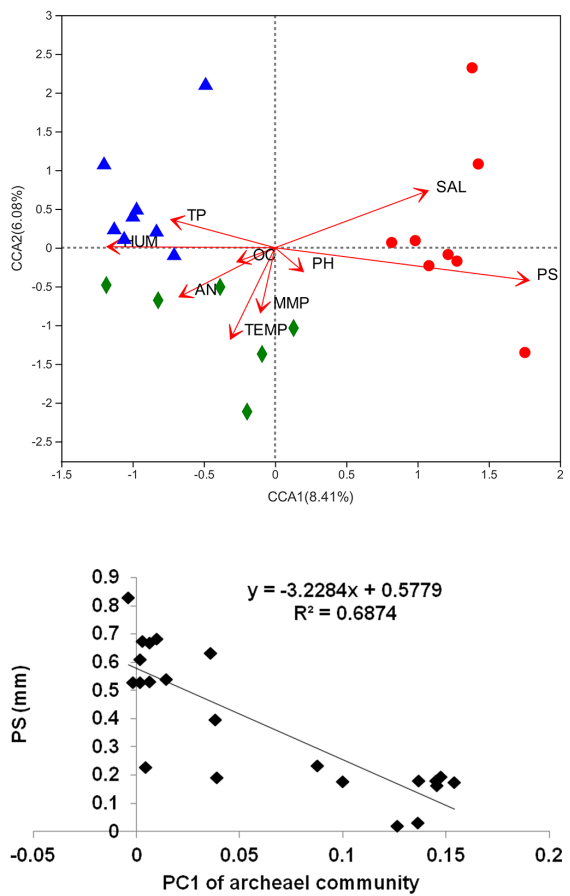

Fungi
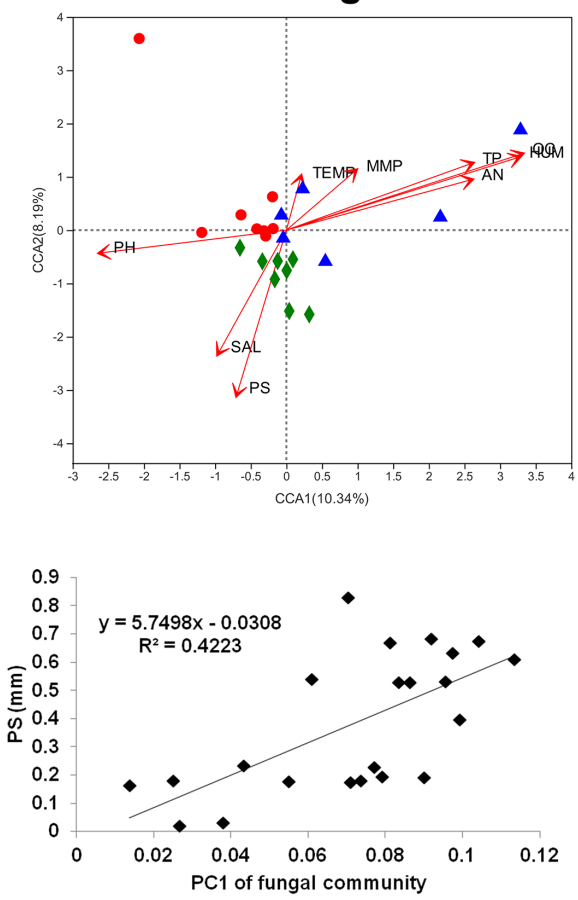

- TLG

Figure 4

(A) Canonical correlation analysis results of the microbial communities in mangrove sediments. Particle size (PS), salinity, and humidity were significant influencing factors for bacterial, archaeal, and fungal communities ( $x \leq 0.05$, see Table S4). (B) Fitting models of PS with the PC1 values from the principal component analysis results of bacterial, archaeal, and fungal communities (see Figs. S8-S10 for the fitting results of other abiotic factors with the PC1 values). Among these results, the fitting models of PS possessed the highest R2 values and significant $p$ values ( $p \leq 0.05)$, suggesting that PS was the key shaping abiotic factor among the factors collected for the bacterial, archaeal, or fungal communities.
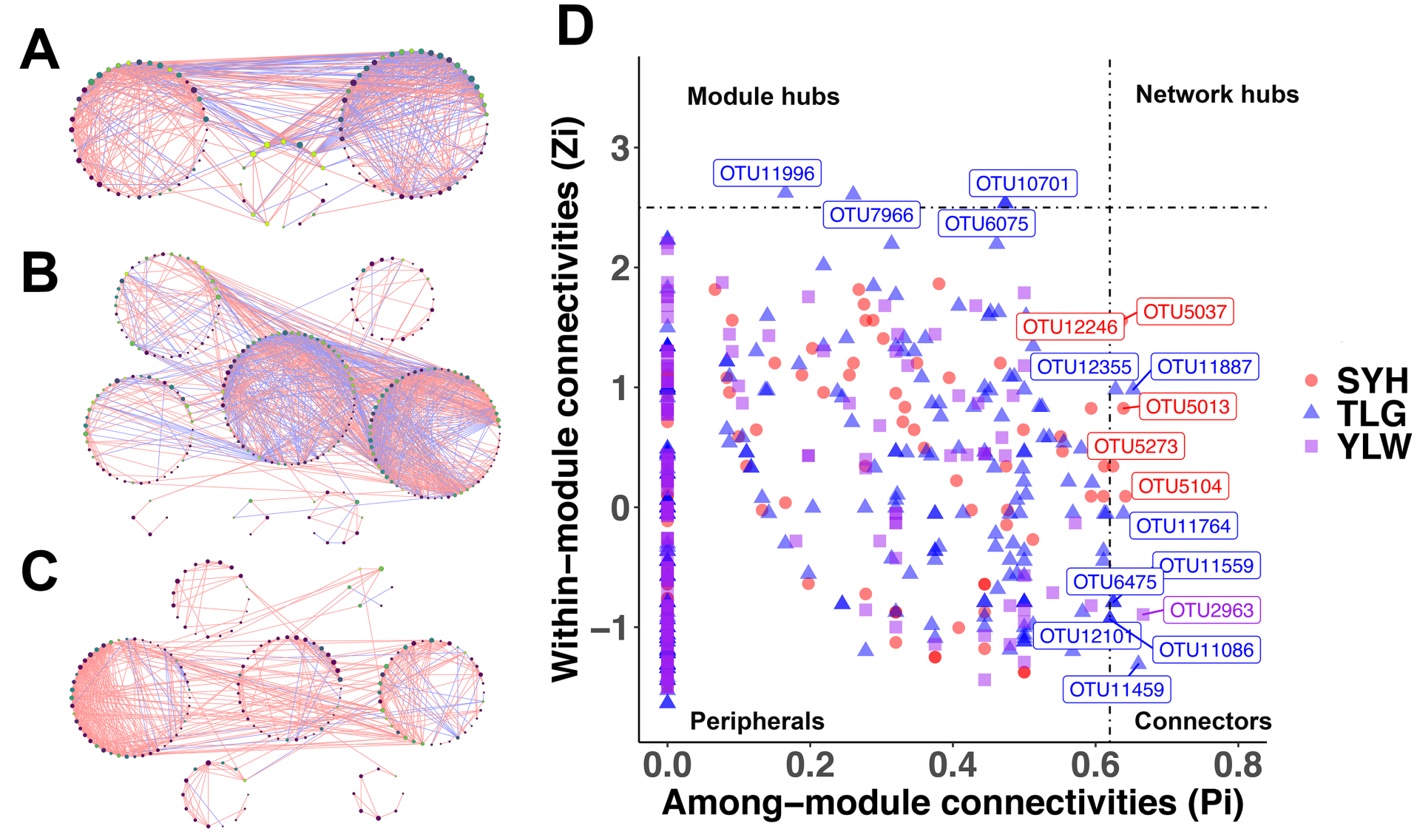

Figure 5 
Co-occurrence networks of the bacterial community from SYH (A), TLG (B), and YLW (C) samples. The point size was positively correlated with the withinmodule connectivities $(\mathrm{Zi})$, and the point color was correlated with the among-module connectivities (Pi). The blue lines indicated negative interaction, while the red lines indicated positive interaction between the OTUs linked by these lines (see Figs. S11-S13 for detailed legend information). Based on the network analysis, the OTUs with $\mathrm{Zi}>2.5$ or/and $\mathrm{Pi}>0.62$ were identified as keystone taxa (D).

\section{Supplementary Files}

This is a list of supplementary files associated with this preprint. Click to download.

- supplement9.xls

- supplement10.xlsx

- supplement11.docx 